\title{
Chemotaxonomic study on Thymus villosus from Portugal
}

\author{
Lígia R. Salgueiro ${ }^{\mathrm{a}, *}$, Roser Vila ${ }^{\mathrm{b}}$, Xavier Tomàs ${ }^{\mathrm{c}}$, \\ Salvador Cañigueral ${ }^{\mathrm{b}}$, Jorge Paiva ${ }^{\mathrm{d}}$, \\ António Proença da Cunha ${ }^{a}$, Tomàs Adzet ${ }^{b}$
}

\author{
${ }^{a}$ Laboratório de Farmacognosia, Faculdade de Farmácia, Universidade de Coimbra, Rua do Norte, \\ 3000 Coimbra, Portugal \\ ${ }^{\mathrm{b}}$ Unitat de Farmacologia i Farmacognòsia, Facultat de Farmàcia, Universitat de Barcelona, Av. Diagonal, 643. \\ E-08028 Barcelona, Spain \\ 'Departament de Quimiometria, Institut Químic de Sarrià. E-08017 Barcelona, Spain \\ ${ }^{\mathrm{d}}$ Instituto Botânico, Universidade de Coimbra. 3000 Coimbra, Portugal
}

Received 15 February 1999; accepted 29 June 1999

\begin{abstract}
The composition of the essential oils of four populations of Thymus villosus subsp. lusitanicus (Boiss.) Coutinho from Portugal was investigated by GC and GC-MS. To study the chemical polymorphism the results obtained from GC analyses of the volatile oils from individual plants from four populations were submited to Principal Component and Cluster analyses. A comparision with the essential oil of T. villosus subsp. villosus, previously studied by us was done. Important differences with regard to the major constituents in these two taxa were found. Linalool, geranyl acetate, geraniol and terpinen-4-ol were the main components of the essential oils of $T$. villosus subsp. lusitanicus, whereas in the oil of T. villosus subsp. villosus p-cymene, myrcene and $\alpha$-terpineol were the major ones. Although, both taxa showed chemical polymorphism, different types of essential oils were characterized in each one: linalool; linalool/ terpinen-4-ol/trans-sabinene hydrate; linalool/1,8-cineole; geranyl acetate/geraniol; geranyl acetate/geraniol/1,8-cineole in T. villosus subsp. lusitanicus and p-cymene/camphor/linalool; $p$-cymene/borneol; linalool/geraniol/geranyl acetate; $\alpha$-terpineol/camphor/myrcene in $T$. villosus subsp. villosus. Thus, the two subspecies of $T$. villosus can be easely differenciated by the composition of their essential oils. (C) 2000 Elsevier Science Ltd. All rights reserved.
\end{abstract}

Keywords: Thymus villosus subsp. lusitanicus; Thymus villosus subsp. villosus; Lamiaceae; Essential oils; Infraspecific variability; Chemotaxonomy; Multivariate analysis

*Corresponding author. Tel.: + 351-39-410-9995; fax: + 351-39-82716. 


\section{Introduction}

Thymus villosus L. belongs to the section Pseudothymbra Bentham of the genus Thymus L. Morales (1986) recognized two subspecies, T. villosus subsp. villosus and T. villosus subsp. lusitanicus (Boiss.) Coutinho. The former has coloured and dentate bracts, corolla up to $10 \mathrm{~mm}$ long and is an endemic plant from central and southeastern Portugal, while the latter has uncoloured bracts, corolla up to $6.5 \mathrm{~mm}$ long and is an Iberian endemic plant (Estremadura and Beira Litoral provinces from Portugal and Cáceres, Ciudad Real and Toledo from Spain). Nevertheless, the latter has a large polymorphism perhaps due to its scattered distribution. In central part of Portugal the two subspecies have similar distribution. So, in that area, sometimes it is difficult to distinguish these two taxa. In previous studies, we already demonstrated the existence of several chemotypes in the essential oil of T. villosus subsp. villosus (Salgueiro et al., 1997). Thus, the aim of this paper is to investigate the composition and infraspecific variability of the essential oils of T. villosus subsp. lusitanicus from Portugal, which had not been previously reported in the literature, and compare the results found for both subspecies of $T$. villosus in order to distinguish them through the composition of their essential oils.

In Spain, Pérez-Alonso and Velasco-Negueruela (1984) studied the essential oils of three populations, one of which (Toledo) had camphor and borneol as major compounds whereas the other ones (Cáceres and Ciudad Real) showed high amounts of camphor, linalool and 1,8-cineole. Later, Morales (1986) reported camphor and borneol as the major compounds in a sample from Toledo.

We now report on the results obtained for the essential oil composition and variability of $T$. villosus subsp. lusitanicus from Portugal. For that purpose, four different sampling sites were chosen, and the qualitative and quantitative analysis of the volatile oil of a representative population sample of each one was performed by GC and GC-MS. To study the infraspecific variability, the oils of individual plants from each locality were analysed mainly by GC, and the data obtained were submitted to principal component analysis and cluster analysis, in order to detect some pattern distribution of individual plants and to identify which constituents can differentiate the groups of individuals.

\section{Material and methods}

\subsection{Plant material}

Aerial parts of the plants were collected at the flowering stage, in June 1992, in the Beira Litoral and Estremadura provinces of Portugal: S. Jorge (A), Azóia (B), Moita Lina-Porto de Mós (C) and Serra do Bouro (D).

Voucher specimens of each population were deposited in the Herbarium of the Instituto Botânico of the University of Coimbra, Portugal (COI).

In order to study the chemical polymorphism, 63 individual plants were also collected. These individuals were collected at random in the same localities at the 
same time that the corresponding representative population samples in order to reduce seasonal variability.

\subsection{Analysis of the essential oils}

The essential oil content of the air-dried plant material was determined according to the European Pharmacopoeia method (Conseil de l' Europe, 1983). Analyses of the essential oils of the representative population samples obtained by water distillation were carried out by GC and GC-MS using fused silica capillary columns with two different stationary phases (Carbowax 20M and Methylsilicone SE-30), as previously described (Adzet et al., 1989; Salgueiro et al., 1995). Components were identified by comparison of their retention indices, relative to a homologous series of fatty acid methyl esters, and mass spectra, with those in our library, literature data and authentic samples.

The quantification of the components was made on the basis of their GC peak areas on the two columns.

\subsection{Chemical polymorphism}

The essential oil of each individual plant was analyzed by GC and GC-MS on the two stationary phases, using the same analytical conditions indicated above. From all the constituents, those which showed a percentage equal or higher than $2 \%$ were selected to be included in the multivariate analysis $(20$ constituents $\times 63$ individuals $=1260$ data). Selected constituents are shown in Table 1 .

All data were processed by PARVUS (Forina et al., 1988) and ESTATS (Tomàs et al., 1988) chemometric packages.

The whole data set was analyzed by principal component analysis in order to prove if it can be projected in the space defined by the three first principal components and the projection coordinates of each individual in that reduced space ("scores") were evaluated for their posterior graphical presentation.

Cluster analysis was also applied to all individuals data, using the euclidean distance between individuals as an index of their similarity and clustering was performed according to the weighed average linkage method. If clusters are defined, they are also denoted in the graphical presentation of individual scores.

\section{Results and discussion}

The average yield of essential oil of the air-dried aerial parts of the four populations of T. villosus subsp. lusitanicus was $1.2 \%$ (v/w). More than $95 \%$ ( 86 compounds) of the volatile constituents were identified in each sample. Table 1 shows the tabulated results. Compounds are listed in order of their elution on a carbowax 20M column. Oxygenated monoterpenes were the main group of constituents in all populations $(67.2-75.4 \%)$. Nevertheless, important differences in the amounts of the major constituents were found, mainly of linalool (24.5-9.0\%), geranyl acetate $(23.9-11.5 \%)$, 
Table 1

Composition of the essential oils of four populations of Thymus villosus subsp. lusitanicus from Portugal

\begin{tabular}{|c|c|c|c|c|}
\hline \multirow[t]{2}{*}{ Components $^{\mathrm{a}}$} & \multicolumn{4}{|c|}{$\%$ in sample } \\
\hline & A & $\mathrm{B}$ & $\mathrm{C}$ & $\mathrm{D}$ \\
\hline Tricyclene & - & 0.1 & $\mathrm{t}$ & - \\
\hline$\alpha$-Thuyene & 1.0 & 0.7 & 0.9 & 0.6 \\
\hline$\alpha$-Pinene & 1.1 & 0.7 & 1.1 & 0.6 \\
\hline Camphene & 0.3 & 1.1 & 0.3 & 0.1 \\
\hline$\beta$-Pinene & 1.0 & 0.5 & 1.1 & 0.5 \\
\hline Sabinene & 1.1 & 0.6 & 0.4 & 0.8 \\
\hline Myrcene $^{\mathrm{b}}$ & 3.1 & 4.2 & 2.1 & 0.8 \\
\hline$\alpha$-Phellandrene & 0.2 & $\mathrm{t}$ & 0.1 & $\mathrm{t}$ \\
\hline$\alpha$-Terpinene & 1.3 & 0.6 & 1.3 & $\mathrm{t}$ \\
\hline Limonene $^{\mathrm{b}}$ & 1.3 & 1.1 & 1.3 & 2.0 \\
\hline 1,8 -Cineole ${ }^{\mathrm{b}}$ & 1.1 & 4.7 & 1.0 & 5.0 \\
\hline cis- $\beta$-Ocimene & 0.1 & 0.1 & 0.1 & 0.1 \\
\hline trans- $\beta$-Ocimene & 0.3 & 0.9 & 0.2 & 0.8 \\
\hline$\gamma$-Terpinene ${ }^{b}$ & 5.5 & 1.4 & 4.8 & 1.0 \\
\hline Octan-3-one & - & 0.3 & $\mathrm{t}$ & 0.2 \\
\hline$p$-Cymene ${ }^{\mathrm{b}}$ & 5.0 & 1.6 & 4.0 & 1.7 \\
\hline Terpinolene & 1.0 & 0.3 & 1.0 & 0.2 \\
\hline 1-Octen-3-yl acetate & 0.1 & $\mathrm{t}$ & 0.1 & 0.1 \\
\hline Octan-3-ol & $\mathrm{t}$ & 0.1 & 0.1 & 0.1 \\
\hline Nonanal & $\mathrm{t}$ & 0.2 & 0.1 & $\mathrm{t}$ \\
\hline Oct-1-en-3-ol & 0.1 & 0.3 & 0.1 & 0.2 \\
\hline$c i s$-Linalool oxide & 0.3 & 0.3 & 0.2 & 0.1 \\
\hline$\alpha-p$-Dimethylstyrene & 0.1 & 0.2 & $\mathrm{t}$ & 0.2 \\
\hline \multicolumn{5}{|l|}{ trans-Sabinene } \\
\hline hydrate $^{b}$ & 2.0 & 2.0 & 3.8 & 1.6 \\
\hline trans-Linalool oxide & 0.1 & 0.1 & 0.1 & $\mathrm{t}$ \\
\hline Campholenal & $\mathrm{t}$ & 0.1 & $\mathrm{t}$ & $\mathrm{t}$ \\
\hline$\beta$-Bourbonene & 0.1 & $\mathrm{t}$ & $\mathrm{t}$ & $\mathrm{t}$ \\
\hline Camphor & 0.4 & 2.0 & 0.4 & 0.1 \\
\hline Linalool $^{\text {b }}$ & 12.0 & 9.0 & 24.5 & 24.0 \\
\hline \multicolumn{5}{|l|}{ cis-Sabinene } \\
\hline hydrate $^{\mathrm{b}}$ & 0.5 & 2.0 & 2.0 & 0.8 \\
\hline$\alpha$-Gurjunene & $\mathrm{t}$ & - & $\mathrm{t}$ & 0.1 \\
\hline Linalyl acetate ${ }^{\mathrm{b}}$ & $\mathrm{t}$ & 1.1 & 1.1 & 0.3 \\
\hline Pinocarvone & $\mathrm{t}$ & $\mathrm{t}$ & $\mathrm{t}$ & 0.1 \\
\hline Bornyl acetate & 0.3 & 0.1 & 0.3 & 0.1 \\
\hline$\beta$-Elemene & - & 0.3 & $\mathrm{t}$ & 0.4 \\
\hline Terpinen-4-ol ${ }^{\mathrm{b}}$ & 13.0 & 5.0 & 15.2 & 5.5 \\
\hline$\beta$-Caryophyllene & 0.5 & 1.1 & 1.1 & 1.1 \\
\hline cis-Dihydrocarvone & 0.2 & - & 0.2 & - \\
\hline allo-Aromadendrene & 0.2 & 0.4 & 0.2 & 0.4 \\
\hline cis-Verbenol & $\mathrm{t}$ & - & $\mathrm{t}$ & - \\
\hline$\delta$-Terpineol & 0.3 & 0.3 & 0.4 & 0.3 \\
\hline trans-Verbenol & 0.1 & 0.2 & 0.1 & $\mathrm{t}$ \\
\hline$\alpha$-Humulene & - & - & $\mathrm{t}$ & - \\
\hline Neral $^{\mathrm{b}}$ & 0.6 & 0.9 & 0.2 & 1.8 \\
\hline$\alpha$-Terpineol ${ }^{\mathrm{b}}$ & 0.8 & 2.6 & 1.2 & 1.5 \\
\hline$\alpha$-Terpinyl acetate & 0.2 & 0.2 & 0.3 & 0.2 \\
\hline Borneol & 0.1 & 0.8 & 0.5 & 0.3 \\
\hline Geranyl formate & $\mathrm{t}$ & 0.1 & - & 0.1 \\
\hline
\end{tabular}


Table 1 - continued

\begin{tabular}{|c|c|c|c|c|}
\hline \multirow[t]{2}{*}{ Components $^{\mathrm{a}}$} & \multicolumn{4}{|c|}{$\%$ in sample } \\
\hline & A & $\mathrm{B}$ & $\mathrm{C}$ & $\mathrm{D}$ \\
\hline$\gamma$-Muurolene & 0.1 & $\mathrm{t}$ & $\mathrm{t}$ & 0.1 \\
\hline Germacrene D & 0.1 & 0.1 & 0.1 & 0.1 \\
\hline Neryl acetate & 0.5 & 0.3 & 0.2 & 0.3 \\
\hline Geranial $^{\mathrm{b}}$ & 0.9 & 1.8 & 0.3 & 2.0 \\
\hline Carvone & 0.1 & $\mathrm{t}$ & 0.1 & - \\
\hline Geranyl acetate ${ }^{b}$ & 23.9 & 19.1 & 11.5 & 14.3 \\
\hline Citronellol & $\mathrm{t}$ & $\mathrm{t}$ & - & 0.3 \\
\hline$\delta$-Cadinene & 0.4 & 0.3 & 0.4 & 0.5 \\
\hline Nerol & 0.4 & 0.3 & 0.2 & 0.9 \\
\hline Geranyl isobutyrate & 0.1 & $\mathrm{t}$ & $\mathrm{t}$ & 0.2 \\
\hline Geranyl propionate & $\mathrm{t}$ & 0.1 & $\mathrm{t}$ & $\mathrm{t}$ \\
\hline trans-Carveol & 0.1 & $\mathrm{t}$ & 0.1 & $\mathrm{t}$ \\
\hline Cuparene & $\mathrm{t}$ & 0.4 & $\mathrm{t}$ & $\mathrm{t}$ \\
\hline Geraniol $^{\mathrm{b}}$ & 8.1 & 18.0 & 7.2 & 14.0 \\
\hline$p$-Cymene-8-ol & $\mathrm{t}$ & 0.1 & $\mathrm{t}$ & 0.2 \\
\hline Geranyl butyrate & 0.3 & 0.7 & 0.1 & 0.6 \\
\hline Geranyl isovalerate & 0.3 & 0.5 & 0.1 & 0.5 \\
\hline $\begin{array}{l}\beta \text {-Caryophyllene } \\
\text { oxide }^{\mathrm{b}}\end{array}$ & 0.2 & 1.6 & 0.2 & 0.3 \\
\hline Ledol & $\mathrm{t}$ & 0.2 & $\mathrm{t}$ & 0.2 \\
\hline E-Nerolidol & 1.2 & 0.1 & 0.9 & 0.1 \\
\hline Cubenol & $\mathrm{t}$ & 0.5 & $\mathrm{t}$ & 0.1 \\
\hline$\beta$-Elemol ${ }^{\mathrm{b}}$ & 0.5 & 0.5 & 0.4 & 2.0 \\
\hline Viridiflorol & 0.2 & 0.2 & 0.2 & 0.3 \\
\hline Geranyl caproate & $\mathrm{t}$ & 0.1 & - & 0.2 \\
\hline Cuminic alchool & 0.1 & 0.1 & $\mathrm{t}$ & - \\
\hline Spathulenol & 0.1 & 0.3 & 0.1 & - \\
\hline Eugenol & 0.2 & $\mathrm{t}$ & 0.1 & - \\
\hline$\gamma$-Eudesmol & 0.1 & $\mathrm{t}$ & 0.1 & 0.3 \\
\hline T-Cadinol ${ }^{\mathrm{b}}$ & 0.3 & 0.6 & 0.3 & 0.6 \\
\hline Thymol & 0.1 & 0.1 & 0.1 & - \\
\hline T-Muurolol & - & - & - & 0.3 \\
\hline Carvacrol & - & $\mathrm{t}$ & - & - \\
\hline$\alpha$-Elemol & - & - & - & $\mathrm{t}$ \\
\hline$a$-Eudesmol & 0.2 & $\mathrm{t}$ & 0.1 & - \\
\hline$\alpha$-Cadinol & 0.2 & 0.8 & 0.2 & 0.8 \\
\hline$\beta$-Eudesmol & $\mathrm{t}$ & - & $\mathrm{t}$ & 0.1 \\
\hline Intermedeol $^{\mathrm{b}}$ & 0.2 & 1.2 & 0.3 & 1.3 \\
\hline Eugenyl acetate & - & $\mathrm{t}$ & - & - \\
\hline Monoterpene hydrocarbons & 22.4 & 14.2 & 18.8 & 9.5 \\
\hline Oxygenated monoterpenes & 67.2 & 72.9 & 71.6 & 75.4 \\
\hline Sesquiterpene hydrocarbons & 1.5 & 2.7 & 2.0 & 2.8 \\
\hline Oxygenated sesquiterpenes & 3.3 & 6.1 & 2.9 & 6.4 \\
\hline Others & 0.6 & 1.0 & 0.5 & 0.7 \\
\hline Total identified & 95.0 & 96.9 & 95.8 & 94.8 \\
\hline
\end{tabular}

$t$ : traces $(\leqslant 0.05 \%)$

${ }^{\mathrm{a}}$ Compounds are listed in order of their elution from a Carbowax 20M column.

${ }^{\mathrm{b}}$ Constituents selected for the multivariate analysis. 
geraniol (18.0-7.0\%) and terpinen-4-ol (15.2-5.0\%). The results showed some important differences between the populations, indicating the existence of chemical polymorphism, as it happened in Spain. Meanwhile, the essential oils of the Portuguese plants can be easely distinguished from the Spanish ones. The latter have higher amounts of camphor, borneol and 1,8-cineole than the Portuguese ones, and

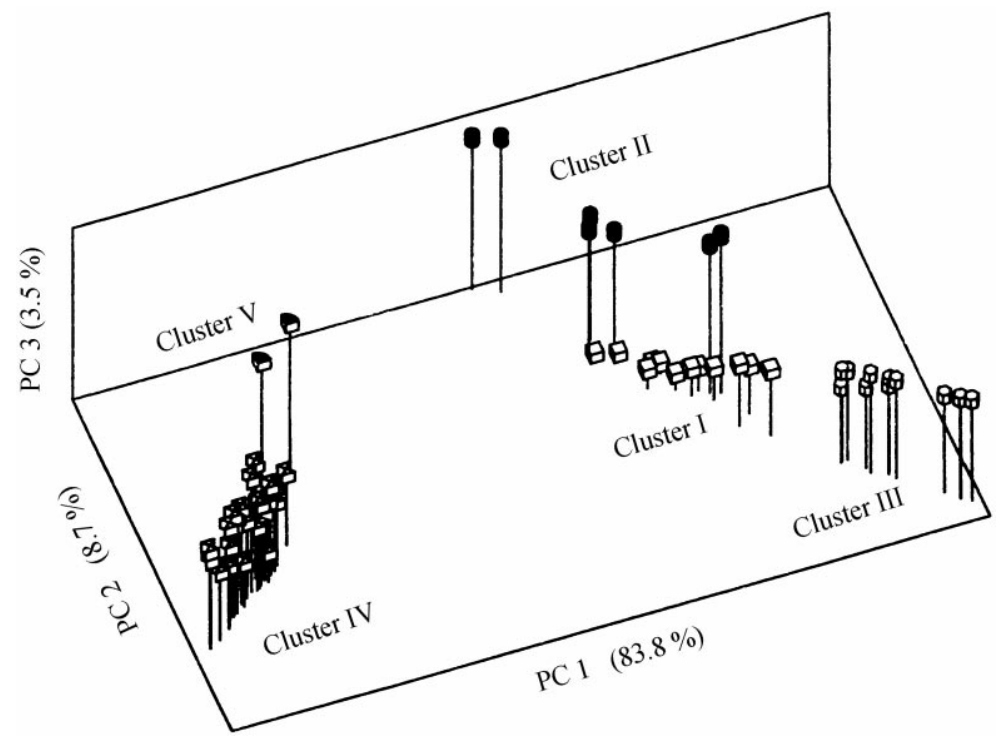

Fig. 1. Relative position of individuals of T. villosus subsp. lusitanicus in the space defined by the first three Principal components.

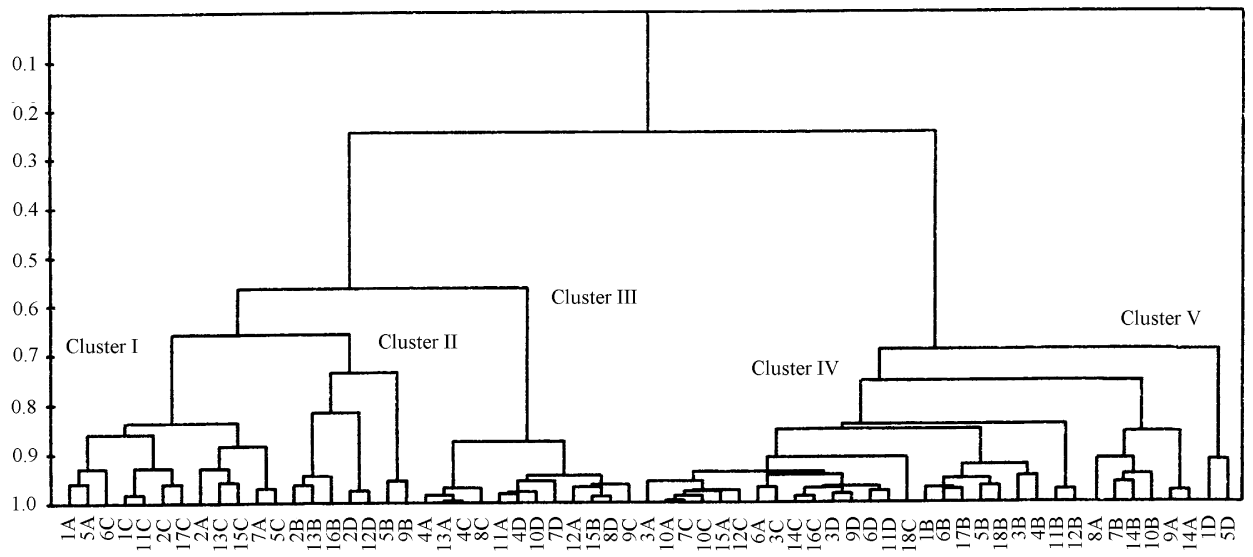

Fig. 2. Two-dimensional dendrogram obtained in the cluster analysis of the essential oils of individual plants of T. villosus subsp. lusitanicus. Horizontal: samples analysed. Vertical: similarity levels between samples. 

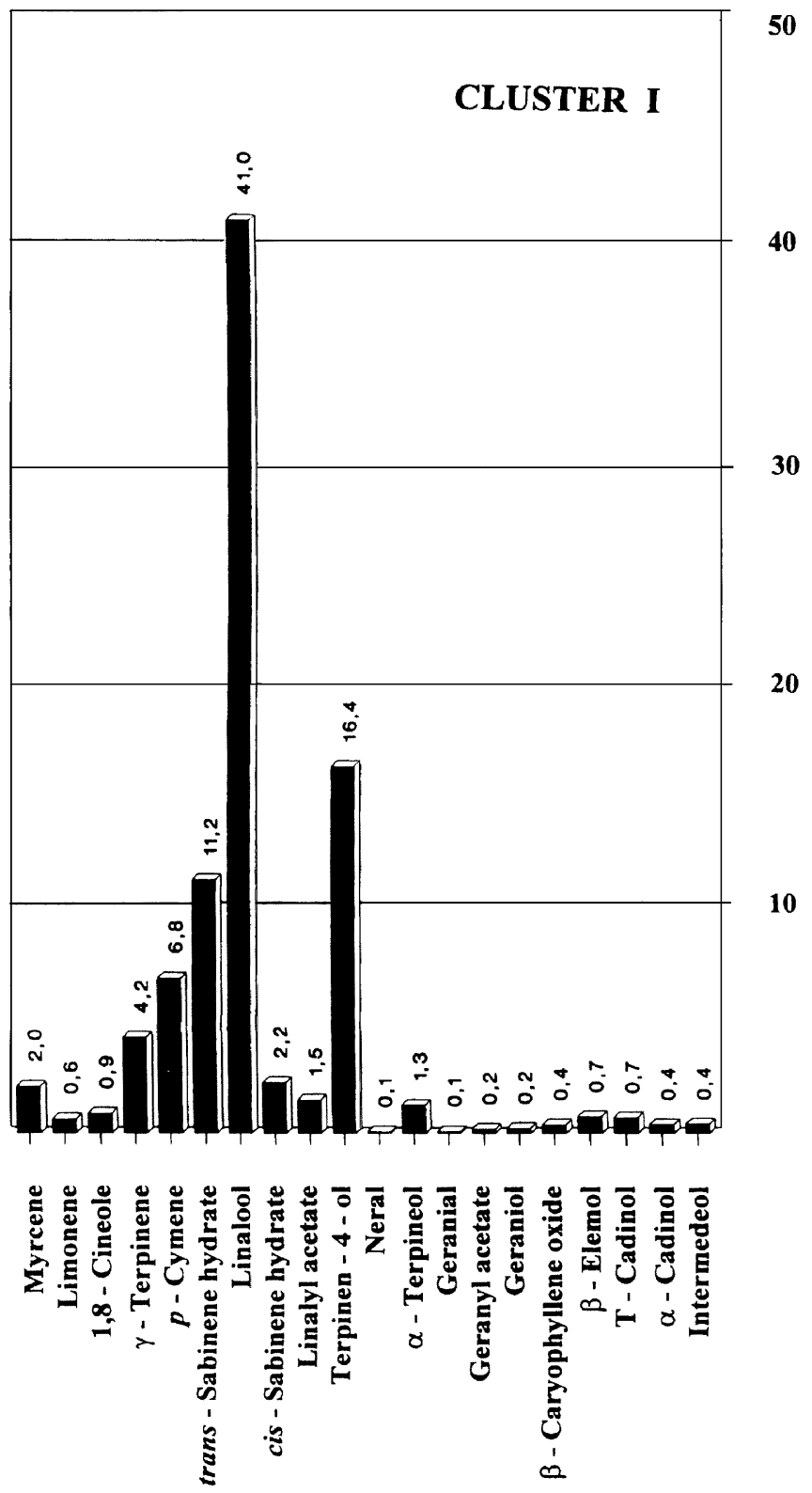

Fig. 3. Mean chemical composition of essential oil of cluster I of T. villosus subsp. lusitanicus. Vertical: mean percentage in the essential oil.

neither geranyl acetate nor geraniol (Pérez-Alonso and Velasco-Negueruela, 1984), while in the Portuguese essential oils these two compounds have always high percentages. 

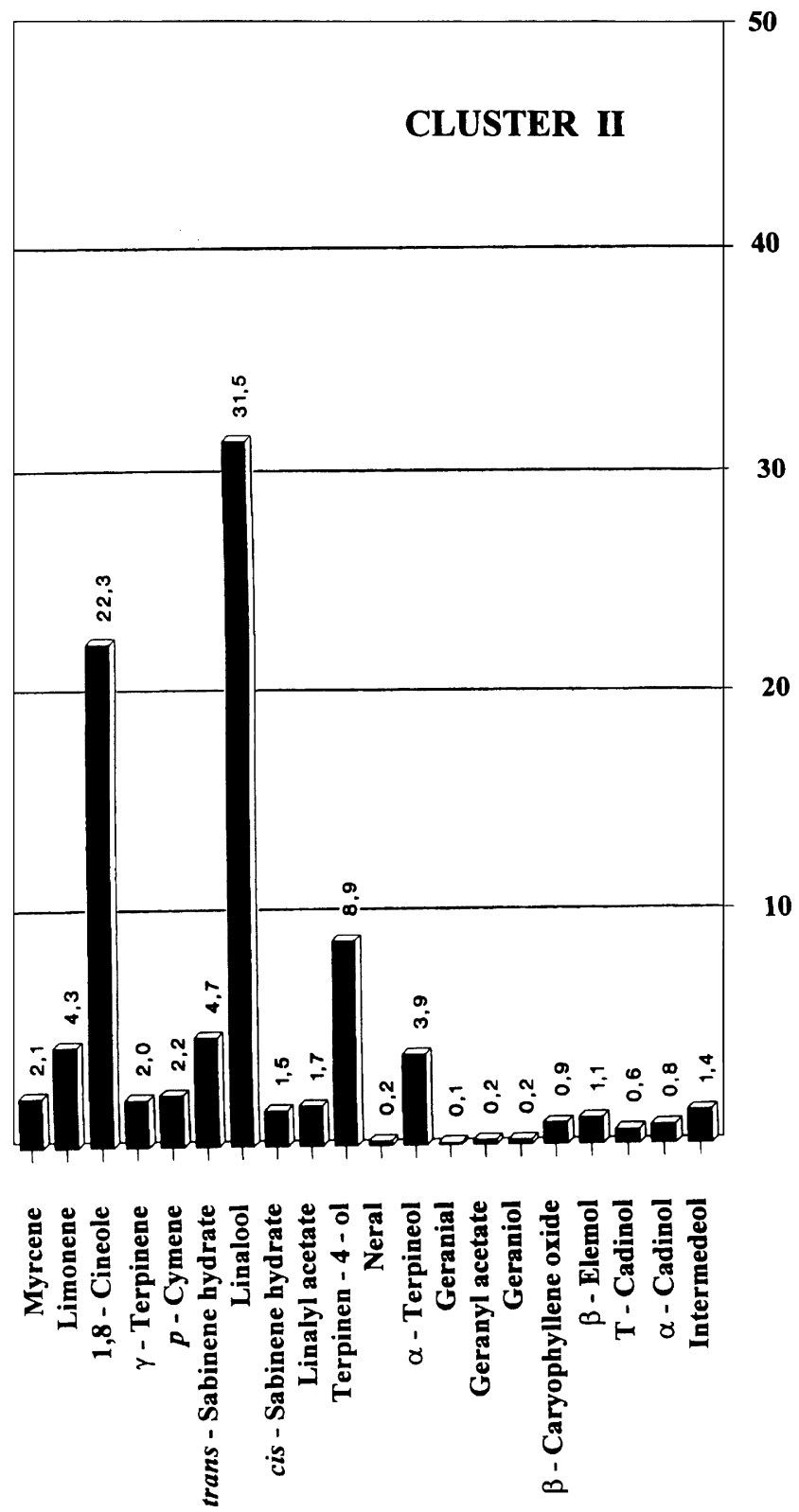

Fig. 4. Mean chemical composition of essential oil of cluster II of T. villosus subsp. lusitanicus. Vertical: mean percentage in the essential oil.

The application of multivariate analysis techniques to the results obtained in the analysis of the essential oils of individual plants allowed us to establish two main types of essential oils: linalool and geraniol/geranyl acetate. Although in both types some 

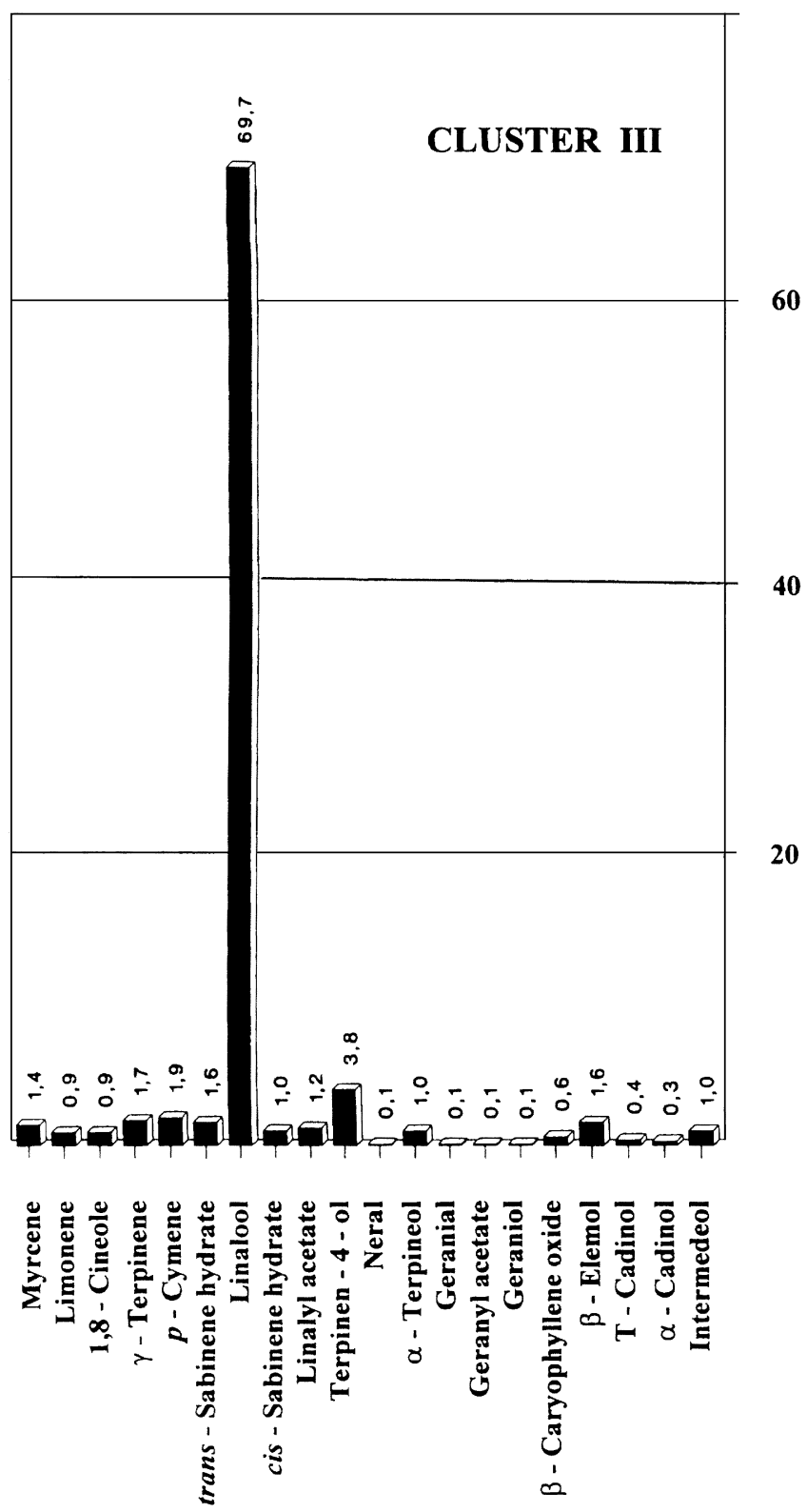

Fig. 5. Mean chemical composition of essential oil of cluster III of T. villosus subsp. lusitanicus. Vertical: mean percentage in the essential oil.

subgroups could be differentiated by the cluster analysis and principal component analysis (Figs. 1 and 2, respectively), as the first three components from PCA accounted for $83.8,8.7$ and $3.5 \%$ of the total variation. Cluster I was characterized by 

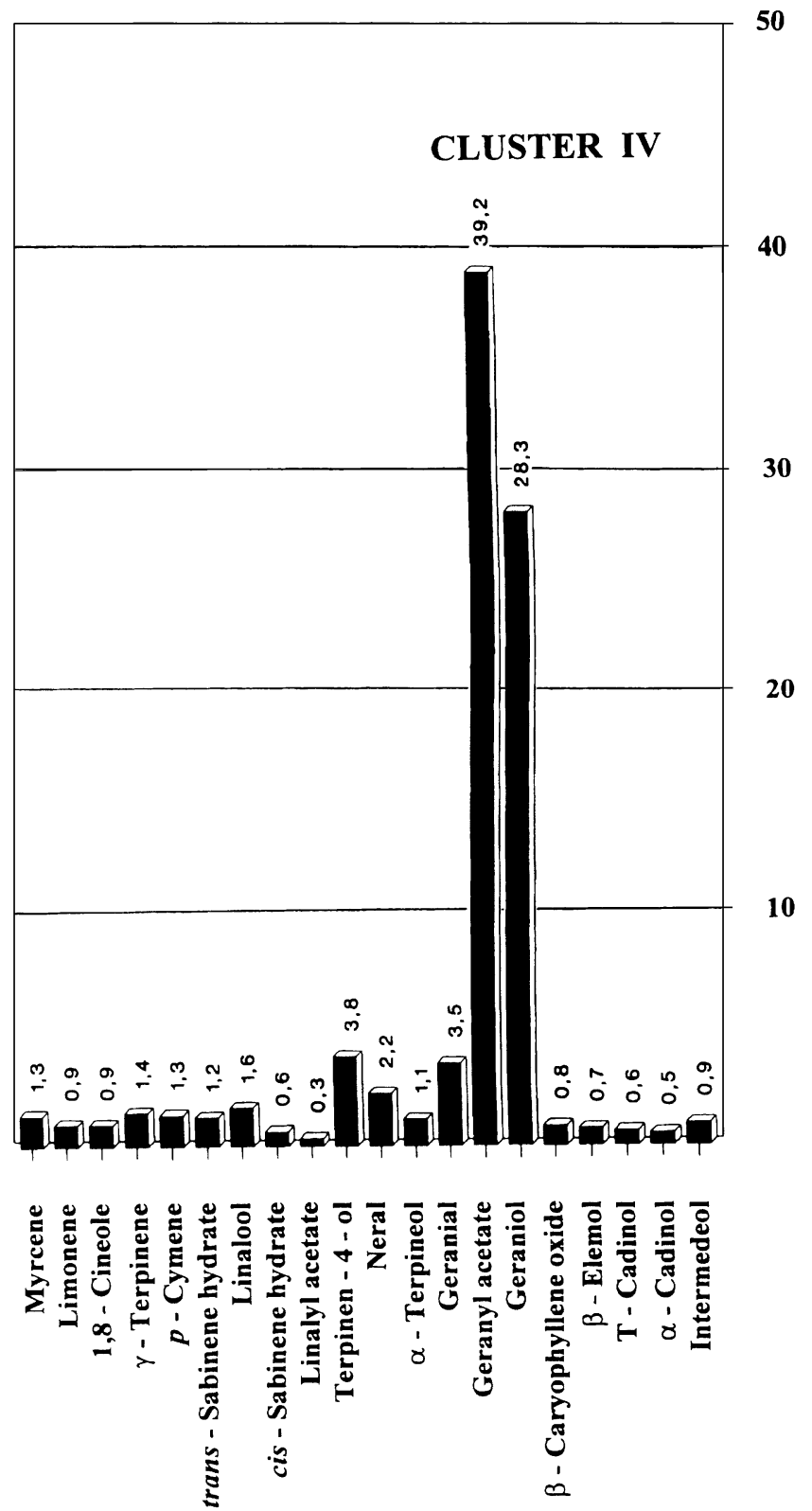

Fig. 6. Mean chemical composition of essential oil of cluster IV of T. villosus subsp. lusitanicus. Vertical: mean percentage in the essential oil.

a high percentage of linalool, terpinen-4-ol and trans-sabinene hydrate (average 41.0, 16.4 and $11.2 \%$, respectively; $19.1 \%$ of the samples analyzed); Cluster II had linalool and 1,8-cineole as the major compounds (average 31.5 and $22.3 \% ; 11.1 \%$ of the 


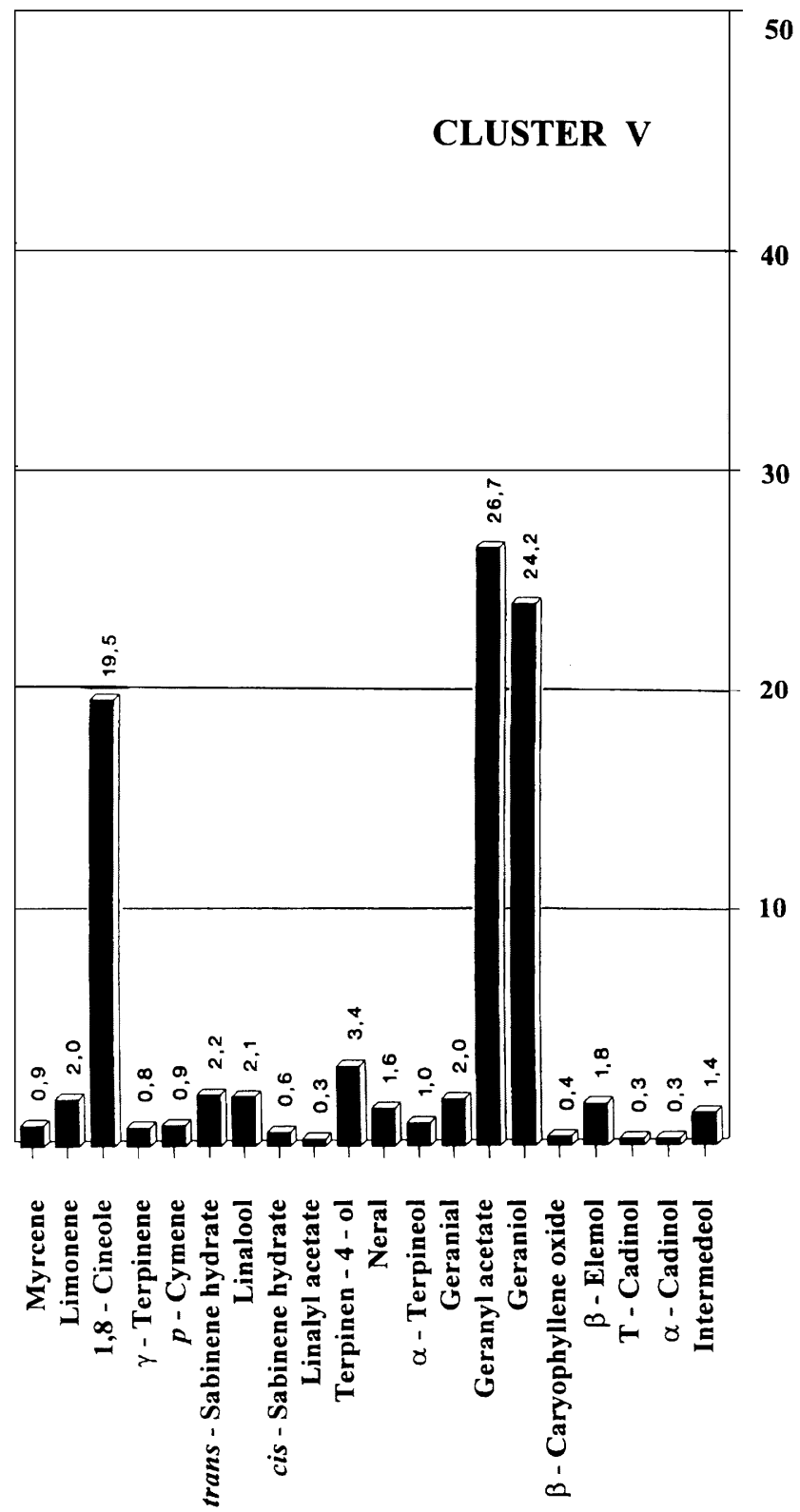

Fig. 7. Mean chemical composition of essential oil of cluster $\mathrm{V}$ of $T$. villosus subsp. lusitanicus. Vertical: mean percentage in the essential oil.

samples analyzed); in Cluster III linalool was the main constituent (average 69.7\%; $19.0 \%$ of the samples analyzed); Cluster IV is characterzed by a high rate of geranyl acetate and geraniol (average 39.2 and $28.3 \% ; 47.6 \%$ of the samples analyzed); and, 
finally, Cluster V showed substantial percentages of geranyl acetate, geraniol and 1,8-cineole (average 26.7, 24.2 and $19.5 \% ; 3.2 \%$ of the samples analyzed). The mean chemical composition of the essential oil of each cluster is presented in Figs. 3-7.

In conclusion, the two subspecies of $T$. villosus can be easely differenciated by the composition of their essential oils. T. villosus subsp. lusitanicus is characterized by a high percentage of oxygenated monoterpenes, whereas $T$. villosus subsp. villosus show large proportions of monoterpenes, either hydrocarbons or oxygenated. In this taxon $p$-cymene was always an important constituent (28.0-10.9\%), excepting one sample which has a high amount of myrcene $(13.0 \%)$ and $\alpha$-terpineol $(16.5 \%)$. In the essential oils of $T$. villosus subsp. lusitanicus $p$-cymene, myrcene and $\alpha$-terpineol attained only 5.0, 4.2 and $2.6 \%$, respectively. So, important differences with regard to the major constituents in these taxa were observed. Both of them showed chemical polymorphism. Nevertheless, different types of essential oils were characterized in each taxon: linalool; linalool/terpinen-4-ol/trans-sabinene hydrate; linalool/1,8cineole; geranyl acetate/geraniol; geranyl acetate/geraniol/1,8-cineole in T. villosus subsp. lusitanicus and $p$-cymene/camphor/linalool; $p$-cymene/borneol; linalool/geraniol/geranyl acetate; $\alpha$-terpineol/camphor/myrcene in T. villosus subsp. villosus.

\section{References}

Adzet, T., Vila, R., Cañigueral, S., Ibáñez, C., 1989. The herb essential oil of Thymus glandulosus Lag. ex H. del Vilar. Flav. Frag. J. 4, 133-134.

Conseil de l'Europe, 1983. Pharmacopée Européenne Vol. 1. Maisonneuve S. A., Sainte Ruffine.

Forina, M., Leardi, R., Armanino, C., Lanteri, S., 1988. Parvus: An Extendable Package of Programs for Data Exploration. Elsevier, Amsterdam.

Morales, R., 1986. Taxonomía del género Thymus L. excluida la Sect. Serpyllum (Miller) Bentham en la Península Ibérica. Ruizia 3, 1-324.

Peréz Alonso, M.J., Velasco Negueruela, A., 1984. Essential oil analysis of Thymus villosus subsp. lusitanicus. Phytochemistry 23, 581-582.

Salgueiro, L.R., Vila, R., Tomàs, X., Tomi, F., Cañigueral, S., Casanova, J., Proença da Cunha, A., Adzet, T., 1995. Chemical polymorphism of the essential oil of Thymus carnosus from Portugal. Phytochemistry 38, 391-396.

Salgueiro, L.R., Vila, R., Tomàs, X., Cañigueral, S., Proença da Cunha, A., Adzet, T., 1997. Essential oil of Thymus villosus subsp. villosus and its chemical polymorphism. Flav. Frag. J. 12, 117-122.

Tomàs, X., Obiols, J., Sol, A., 1988. Application of pattern recognition to speciation data of heavy metals in suspended particulates of urban air. J. Chemometrics 3, 139-150. 